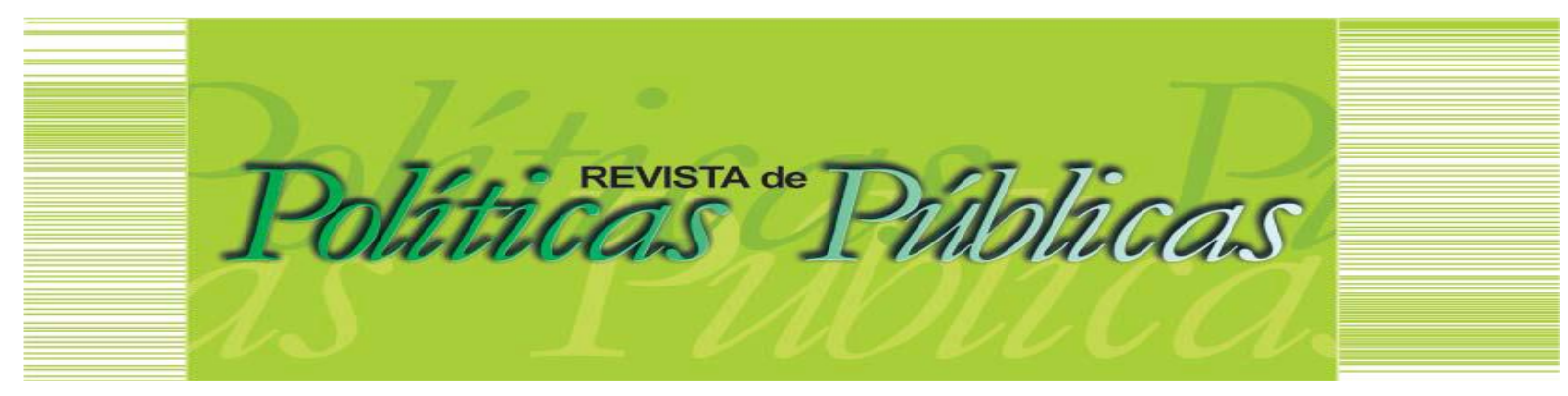

\title{
AS ILUSÕES DO POLICIAMENTO COMUNITÁRIO: \\ O caso da Paraíba
}

Fábio Gomes de França1

\section{Resumo:}

Este trabalho descreve a relação entre o desenvolvimento do policiamento comunitário enquanto política de Segurança Pública e o uso desse projeto pelo aparato policial militar para justificar formas de controle estatal na cidade de João Pessoa, na Paraíba. Tem como base dados obtidos por meio de observação direta e participante e entrevistas semiestruturadas realizadas durante os anos de 2012-2014 com policiais militares (Praças e Oficiais) que participavam do projeto de polícia comunitária, intitulado policiamento solidário. Conclui que o discurso institucional acerca do projeto oculta formas de violência que acabam por sofisticar o controle estatal por meio de uma política de resultados com base na redução de homicídios em detrimento de políticas sociais que possam melhorar as reais condições dos locais onde 0 projeto foi implantado.

Palavras-chave: Policiamento de proximidade. Políticas de segurança pública. Controle social.

THE ILLUSIONS OF THE COMMUNITY POLICING: The case of Paraíba State, Brazil

\begin{abstract}
:
This paper describes the relationship between the development of community policing as a public security policy and the use of this project by the military police apparatus to justify forms of state control in the city of João Pessoa, Paraíba.It is based on data obtained through direct observation and participant and semi-structured interviews carried out during the years 20122014 with military police officers (Squares and Officers) who participated in the community police project, entitled solidarity policing. It concludes that the institutional discourse about the project conceals forms of violence that end up refining state control through a results policy based on the reduction of homicides to the detriment of social policies that can improve the real conditions of the places where the project was implemented..
\end{abstract}

Keywords: Community policing. Public security policies. Social control.

Artigo recebido em: 05/01/2019 Aprovado em: 06/04/2019 DOI: http://dx.doi.org/10.18764/2178-2865.v23n1p62-80

\footnotetext{
${ }^{1}$ Bacharel em Segurança Pública. Doutor e Mestre em Sociologia pela Universidade Federal da Paraíba (UFPB) com pósdoutorado em Direitos Humanos. Professor de Criminologia e Sociologia pelo Centro de Educação da Polícia Militar da Paraíba (PMPB). Endereço Profissional: Rua Coronel Francisco de Assis Veloso, s/n, Mangabeira VII, João Pessoa-PB. CEP 58058-510. E-mail: filhosdalegiao@gmail.com
} 


\section{INTRODUÇÃO}

Neste trabalho, partimos do pressuposto de que, assim como outras polícias militares no Brasil, em meio à efervescência da abertura democrática ocorrida especialmente com a Constituição de 1988, na Paraíba, a filosofia de polícia comunitária também passou a ser uma estratégia utilizada pela Polícia Militar para acompanhar o processo de consolidação democrática. Desse modo, ao longo dos anos e das tentativas para implantar o policiamento comunitário, chegamos atualmente ao projeto de policiamento solidário. No entanto, quanto às tentativas realizadas desde a década de 90 do século passado, no que consistiram os diversos modelos de polícia comunitária testados? E como se caracteriza o atual modelo denominado de policiamento solidário?

$\mathrm{Na}$ verdade, este texto baseia-se em dados etnográficos obtidos durante a feitura de nossa Tese de Doutorado defendida junto ao Programa de Pós-Graduação em Sociologia pela Universidade Federal da Paraíba, entre os anos de 2012-2014. À época, realizamos observação direta e participante nos postos de policiamento solidário e entrevistamos policiais militares (Praças e Oficiais $)^{1}$ envolvidos diretamente com o projeto, que atuavam nos postos e realizavam policiamento ostensivo nos bairros contemplados com a polícia solidária. Entrevistamos também um Coronel e um Major que trabalharam diretamente na implantação dos projetos de policiamento comunitário nas cidades de Sousa e Campina Grande, respectivamente, em anos anteriores ao projeto de policiamento solidário.

Assim, nosso objetivo é descrever como a Polícia Militar paraibana, ao longo do tempo, utilizou estratégias para implantar o policiamento comunitário, culminando com o policiamento solidário, que passou a funcionar a partir de 2011 e até agora se mantém. De todo modo, nosso percurso expõe, com certo recorte, especificamente em relação ao projeto de polícia solidária, a realidade de um dos bairros nos quais ocorre a tentativa de aproximação entre policiais e moradores: presença da criminalidade urbana, pobreza, ausência de condições de moradia e sobrevivência adequadas. Durante a feitura da Tese, etnografamos cinco postos ${ }^{2}$ e observamos como cada um deles apresenta suas peculiaridades, especialmente dependendo de onde se situam.

No entanto, nosso olhar neste texto volta-se apenas para o bairro de Mandacarú/Alto do Céu e, o uso de fotografias de forma expositiva no tópico sobre o policiamento solidário nos ajuda a ter uma noção da realidade social desse local. A escolha da análise do bairro de Mandacarú/Alto do Céu se deveu ao fato de que ele apresenta, segundo o discurso dos policiais militares entrevistados, formas violentas de sociabilidade devido à presença do tráfico de drogas, o que demandou por parte do Estado a implantação do projeto de policiamento solidário. Essa informação nos possibilita entender como se caracteriza a presença da criminalidade no local e as formas de resposta encontradas através 
AS ILUSÕES DO POLICIAMENTO COMUNITÁRIO: o caso da Paraíba

da polícia solidária, tornando a análise do bairro um recorte plausível para a compreensão do projeto de policiamento solidário como um todo.

Portanto, iniciamos mostrando sinteticamente como se deu a emergência do policiamento comunitário no Brasil para, em seguida, chegarmos à Paraíba com suas primeiras experiências de polícia comunitária. Em sequência, destacamos como o modelo de policiamento solidário foi implantado e, pelo que foi apreendido com as observações e entrevistas, descreveremos algumas características do posto de policiamento solidário do bairro de Mandacarú/Alto do Céu, localizado na cidade de João Pessoa.

\section{AS PRIMEIRAS EXPERIÊNCIAS DE POLÍCIA COMUNITÁRIA NO BRASIL}

Diversos autores (CERQUEIRA, 1999; GREENE, 2002; MOORE, 2003; ROSENBAUM, 2002; SKOGAN, 2002; SKOLNICK; BAYLEY, 2002; TROJANOWICZ; BUCQUEROUX, 1994) colaboram para que possamos compreender que o policiamento comunitário trata-se de uma filosofia e de uma estratégia organizacional que possibilita uma nova parceria entre a polícia e a comunidade/sociedade. Por meio de um trabalho conjunto, podem-se resolver problemas relativos ao crime, drogas, medo do crime, os que ocasionam desordens físicas e morais, além da decadência do bairro, de modo que se busque a melhoria na qualidade de vida dos locais onde exista esse tipo de policiamento. Para tanto, é necessário o comprometimento de todos os policiais com um olhar voltado para a prevenção e com ênfase na descentralização do patrulhamento, dando-se maior autonomia e liberdade aos policiais em contato com as pessoas nas ruas. Esse contato visa à aproximação entre policiais e moradores, inclusive pelo fato de o policiamento comunitário privilegiar o patrulhamento a pé, ao invés do uso da viatura tradicional de rádio-patrulhamento. Essas condições exigem a permanência do policial comunitário nas áreas em que atua. Por esse escopo, "[...] o policiamento comunitário impõe uma responsabilidade nova para a polícia, ou seja, criar maneiras apropriadas de associar o público ao policiamento e à manutenção da lei e da ordem." (SKOLNICK; BAYLEY, 2002, p. 18).

No Brasil, os debates sobre o policiamento comunitário iniciaram-se no Rio de Janeiro durante a gestão de Leonel Brizola como governador do Estado na década de 1980, o qual elegeu 0 Coronel Carlos Magno Nazareth Cerqueira (entre os anos de 1983-84 e 1991-94) para ser Comandante Geral da Polícia Militar. O Coronel tornou-se o grande precursor dos estudos sobre policiamento comunitário (ALBERNAZ et al., 2007; BEATO, 2002; LEEDS, 2015; MELO, 2009) em nosso país e foi um dos principais articuladores na implantação dos primeiros projetos no Rio de Janeiro.

A busca pelo desenvolvimento do policiamento comunitário no Brasil caminhou de acordo com a abertura política pós-regime militar e ganhou força com a aprovação da Constituição de 1988, que traz em seu texto um amplo conjunto de garantias individuais e coletivas com destaque para 
princípios como cidadania e segurança, os quais estiveram distantes de serem efetivados durante 0 período de exceção (1964-1985). Além disso, temos que destacar a luta em favor da garantia dos Direitos Humanos que mobilizou a sociedade a exigir, com o novo regime político, instituições policiais com práticas democráticas por parte de seus agentes.

Nesse caminho, as primeiras experiências de policiamento comunitário ocorreram no Espírito Santo, nas cidades de Guaçuí e Alegre, no ano de 1988. No Rio de Janeiro, tivemos, sob a tutela do Coronel Carlos Magno Nazareth Cerqueira, em 1983, a criação do Centro Integrado de Policiamento Comunitário (LEEDS, 2015) e, as experiências no bairro de Copacabana, entre os anos de 1994-95. (MUNIZ et al., 1997). Em São Paulo, o projeto iniciou-se em 1997 com a implementação dos Conselhos Comunitários de Segurança nos bairros. (BEATO, 2002). No entanto, a primeira base em São Paulo só foi instalada em 22 de dezembro de 1998 no Jardim Ângela que, segundo dados da Organização das Nações Unidas à época tratava-se do lugar mais violento do mundo.

Além das experiências apontadas anteriormente, segundo Cerqueira (1999), os Estados em que foram feitas tentativas ou implementações de projetos de policiamento comunitário no Brasil foram: Pará, Paraná, Sergipe, Rio Grande do Norte, Rio Grande do Sul, Distrito Federal, Ceará, Pernambuco, Paraíba, Minas Gerais, Santa Catarina e Bahia. Existem ainda informações sobre a existência de projetos no Amapá3 (Polícia Interativa e de Segurança Social), iniciado em 1998 e, em Rondônia. (GOTTARDO; SILVA, 2011). O que se percebe em meio às diversas experiências no Brasil é a variada nomenclatura adotada pelas polícias estaduais ${ }^{4}$, como exemplos: Ronda do Quarteirão, no Ceará; Polícia Interativa, no Espírito Santo; Policiamento Ostensivo Volante (POVO), no Pará; Polícia Cidadã, na Bahia; Polícia Solidária, na Paraíba e Polícia Pacificadora, no Rio de Janeiro.

No contexto das políticas governamentais, foi lançado no ano 2000, durante o segundo mandato do então Presidente Fernando Henrique Cardoso, o Plano Nacional de Segurança Pública (PNSP) que, "[...] elaborado a partir de consultas ao Gabinete de Segurança Institucional, governos estaduais, universidades e organizações da sociedade civil, definiu pela primeira vez uma política nacional de segurança pública." (MESQUITA NETO, 2011, p. 390). Dentre o conjunto de 124 ações que prescreviam medidas no âmbito do Governo Federal, deste último com os Governos Estaduais, além de medidas de natureza normativa e institucional, no Compromisso $n^{0} 12$, que ressalta a Capacitação Profissional e o Reaparelhamento das Polícias, tem-se que: "[...] é hoje consenso em todo o mundo que a eficiência da polícia está diretamente ligada a sua proximidade da população e ao grau de confiança alcançado junto à comunidade." (BRASIL, 2000).

De acordo com o referido preceito (aproximar polícias e comunidades), temos a Ação de $n^{0} 94$ que sintetiza o "[...] apoio à Capacitação das Polícias Estaduais e Incentivo às Polícias Comunitárias", ou seja, "Apoiar e padronizar a capacitação das polícias estaduais, particularmente na 
gestão de segurança pública, [...] e, especialmente, na implantação de polícias comunitárias, além de promover a integração entre as academias de polícia civil e militar." (BRASIL, 2000). O PNSP ainda previa na Ação de $n^{0} 93$ a criação do Fundo Nacional de Segurança Pública (FNSP), que acabou por ser instituído em 14 de fevereiro de 2001, mediante a Lei $n^{0}$ 10.201, por meio da Medida Provisória $n^{0}$ 2.029, de 20 de junho de 2000. De acordo com o Art. $1^{\circ}$ da Lei $n^{0} 10.201$ dever-se-ia "[...] apoiar projetos de responsabilidade dos Governos dos Estados e do Distrito Federal, na área de segurança pública, e dos Municípios, onde haja guardas municipais." (BRASIL, 2001). Nesse sentido, o Art. 4", Inciso IV, relaciona o apoio a programas de polícia comunitária.

Nesse percurso, no ano de 2009, foi lançada pelo Ministério da Justiça e pela Secretaria Nacional de Segurança Pública (SENASP), a segunda edição da Matriz Curricular Nacional (MCN), que consiste em um compêndio que congrega ações formativas para os profissionais da área de Segurança Pública, inclusive os policiais militares. Destaca-se no conjunto da MCN a Malha Curricular, que diz respeito a "[...] um núcleo comum de disciplinas, agrupadas por áreas temáticas, que congregam conteúdos conceituais, procedimentais e atitudinais, com o objetivo de garantir a unidade de pensamento e ação dos profissionais da área de Segurança Pública." (BRASIL, 2009, p. 35). Como forma de nortear os currículos dos cursos de formação dos policiais militares e cursos à distância promovidos pela SENASP, encontramos na Malha Curricular (quando se leva em consideração a distribuição das disciplinas de acordo com a natureza dos conteúdos), as disciplinas de Fundamentos de Gestão Integrada e Comunitária e Mobilização Comunitária. Na primeira, a polícia comunitária, como filosofia de trabalho integrado, aparece como conteúdo programático e, na segunda, os objetivos da disciplina e o conteúdo programático direcionam-se para o ensino de como se criar condições para que o profissional de Segurança Pública possa construir Conselhos Comunitários de Segurança de modo que, em meio a essa busca,

Qualquer tentativa de trabalho ou programa de Polícia Comunitária deve incluir
necessariamente a comunidade, pois a participação dela é um fator importante na
democratização das questões de Segurança Pública, na implementação de programas
comunitários que proporcionam a melhoria de qualidade de vida e na divisão de
responsabilidades. A compreensão da dinâmica da comunidade é essencial para a
prevenção e controle do crime e da desordem, assim como do medo do crime, pois o
controle e a participação social informal (do coletivo, do grupo) é mais eficaz. Todas as vezes
que grupos de cidadãos, ou moradores, se reúnem para encaminhar soluções para
problemas comuns o resultado é bastante positivo. O desafio, portanto, não está apenas em
promover trabalhos de interesses espećificos com grupos organizados da comunidade, mas
também em trabalhar na organização de trabalhos comunitários de forma constante e
permanente. (BRASIL, 2009, p. 67-68).

O que se constata com a presença de conteúdos sobre policiamento comunitário na MCN é a institucionalização de conhecimentos que visam à efetivação de programas de polícia comunitária por parte das polícias estaduais na formação de seus profissionais. Essas estratégias governamentais aparentemente baseiam-se na crença de que "[...] os investimentos no aparato da repressão, por 
maiores que fossem, eram e são claramente insuficientes para dar conta da criminalidade em sociedades desiguais como as nossas e para diminuir o crime seria preciso contar com a colaboração da comunidade." (KAHN, 2002, p. 9). Por esse viés, a Paraíba também seguiu os ventos que sopram para uma nova forma de policiar com a sociedade, e desde o final da década de 1990 vem fazendo tentativas para implementar projetos de policiamento comunitário.

\section{O POLICIAMENTO COMUNITÁRIO NA PARAÍBA}

Segundo Cerqueira (1999, p. 137), a Polícia Militar da Paraíba desenvolveu um curso de Polícia Comunitária em dezembro de 1997, o qual teve como finalidade "[...] sensibilizar as autoridades da área de segurança pública para a necessidade de mudanças na administração e na filosofia da atuação policial". O curso foi promovido em conjunto pela Polícia Militar da Paraíba com o Instituto Carioca de Criminologia, o Conselho Estadual da Defesa dos Direitos do Homem e do Cidadão, a Universidade Federal da Paraíba e a Secretaria de Trabalho e Serviço Social. No entanto, a disciplina de Policiamento Comunitário já existia desde a feitura da primeira Grade Curricular do Curso de Formação de Oficiais (CFO) da PM paraibana em 1991.

O Plano Estadual de Segurança Pública do Governo da Paraíba (PESP), entre os anos de 2003 e 2006, enfatizava em vários pontos de suas diretrizes a utilização da polícia e do policiamento comunitário como meta de governo. Para tanto, de acordo com um Quadro Diagnóstico Indicativo de Problemas, para superar a mobilização comunitária deficiente propunha-se como medida necessária 0 Curso de Polícia Comunitária, assim como, com a intenção de investir no aperfeiçoamento técnicocientífico de recursos humanos estipulou-se "[...] capacitar, dentro das instituições, agentes multiplicadores nas áreas de Direitos Humanos, Polícia Comunitária e Relações Interpessoais." (PARAÍBA, 2003-2006, p. 19). Assim, para destacar a prevenção como prioridade, o PESP visou implantar a Polícia Comunitária e elencou esse objetivo como medida institucional observando "[...] a Polícia Comunitária como filosofia, estratégia e política de governo, transformando as polícias em instituições democráticas e mais próximas da comunidade." (PARAÍBA, 2003-2006, p. 31). O PESP ainda acentuava o Programa de Desenvolvimento do conceito de Polícia Comunitária explicitando que,

\footnotetext{
A Polícia Comunitária é a essência da atividade policial moderna. Seu fundamento é a estreita colaboração e o estreito relacionamento entre as pessoas da comunidade e destas para com a sua Polícia, tudo em prol da ordem pública. Esse modelo requer programas permanentes de interação povo - polícia, programas esses de informação e educação. É preciso considerar que a Polícia deve estar a serviço da comunidade, no sentido de propiciar ao cidadão 0 exercício de todos os seus direitos, individuais e coletivos que a legislação assegura. Deve ser observado, ainda, que um dos pressupostos desse modelo de Polícia consiste no fato de o próprio policial se sentir um cidadão inserido no contexto social, sincronizado, comprometido e envolvido com os anseios da comunidade. (PARAÍBA, 20032006, p. 44).
} 
AS ILUSÕES DO POLICIAMENTO COMUNITÁRIO: o caso da Paraíba

Na prática, as primeiras experiências de policiamento comunitário na Paraíba ocorreram na cidade de Sousa, no Sertão paraibano, entre os anos de 1998 e 1999. Com informações obtidas mediante entrevista, realizada com o então Tenente-Coronel Sobreira, à época Capitão e Comandante da Companhia de Polícia Militar de Sousa, além de idealizador do projeto, pudemos obter informações que descrevem essa experiência. Segundo o Tenente-Coronel Sobreira a ideia surgiu depois de sua participação no Curso de Gestão em Policiamento Comunitário no ano de 1998, que inclusive teve o Coronel Carlos Magno Nazareth Cerqueira da Polícia Militar do Rio de Janeiro como um dos instrutores. O curso ocorreu no Centro de Ensino da PMPB em parceria com a UFPB e o Núcleo de Direitos Humanos da UFPB. Após o curso, o nosso interlocutor levou a ideia para a cidade de Sousa e, de acordo com suas palavras, ao recordar sobre a notícia exposta por uma repórter de um jornal local que dizia Polícia Comunitária na Paraíba começa por Sousa, ele afirma que tal manchete gerou problemas com seus superiores hierárquicos.

Ainda pelas palavras do Tenente-Coronel Sobreira, o objetivo do projeto em Sousa era "[...] aproximar a polícia do cidadão. Gerar confiança. Estreitar os laços da polícia com os moradores locais para que esse estreitamento venha nos trazer detalhes, informações das situações de problemas existentes naquele bairro." (Informação verbal)5. O projeto foi aplicado em quatro bairros periféricos (Jardim Planalto, Cangote do Urubú - Nossa Senhora de Fátima -, Várzea da Cruz e Mutirão) e um central (Frei Damião), e contou com o apoio principalmente das comunidades e de profissionais liberais como médicos, empresários e professores. As comunidades recebiam serviços gratuitos como corte de cabelo, que eram custeados pelos empresários locais. Na época, a cidade de Sousa tinha uma média de 20 (vinte) homicídios por ano. Uma rádio emissora da cidade também apoiou o projeto, ao contrário do Comando da PM paraibana, que apoiou de forma mínima, segundo o Tenente-Coronel.

Após a experiência de Sousa, poucos anos depois, em 2002, tivemos as experiências do policiamento comunitário nos bairros de Paratibe e Mussumago, em João Pessoa. Os dois bairros, à época, tinham conjuntamente uma população de 13.016 habitantes e apresentavam características de comunidades rurais, visto a falta de estrutura urbana como ruas asfaltadas e redes de esgoto e 0 subemprego temporário era a realidade para a maioria dos moradores. Os projetos surgiram com base nas exigências do Sistema Único de Segurança Pública, já que, o Governo Federal, através da SENASP, fomentou o aumento das experiências de policiamento comunitário. (LIMA; MATIAS DA SILVA, 2010; SILVA, 2007).

No período de 16 de julho a 16 de agosto de 2001 foi iniciada a formação, com o primeiro Curso de Gestão em Policiamento Comunitário, com recursos do Fundo de Amparo ao Trabalhador (FAT), que contou com a participação de policiais militares e membros das comunidades por meio de convênio entre a UFPB e a PMPB. O projeto foi coordenado pelo Centro de Ensino da PMPB e a Pró- 
Reitoria de Extensão e Assuntos Comunitários, a Comissão de Direitos Humanos e a Fundação de Apoio à Pesquisa e à Extensão da UFPB. Ainda apoiaram o projeto $05^{\circ}$ Batalhão de Polícia Militar, a Secretaria de Segurança Pública, o Núcleo de Defesa da Vida, o Centro Profissionalizante Deputado Antônio Cabral e as Comunidades de Paratibe e Santana. Estas últimas apoiaram o projeto juntamente com igrejas católicas e evangélicas que cediam seus espaços para os encontros entre policiais e moradores e para outras atividades que diziam respeito à polícia comunitária. Após a implantação do policiamento comunitário, 11 (onze) policiais foram designados para trabalhar nas comunidades e houve divulgação do programa por parte da comunidade, inclusive com a utilização de uma rádio difusora. (LIMA; MATIAS DA SILVA, 2010; SILVA, 2007). Assim como ocorreu na cidade de Sousa, atualmente o programa está extinto.

Entre os anos de 2002 e 2010, o policiamento comunitário foi implementado na cidade de Campina Grande. Assim como o relato do projeto ocorrido em Sousa, realizamos entrevista com 0 Major Simão, que era Capitão à época do início do projeto e foi um dos idealizadores. Semelhante ao histórico das experiências anteriormente citadas, o Major Simão participou de um Curso sobre Polícia Comunitária em 2002, também no Centro de Ensino da PMPB. O curso durou praticamente um mês, compondo-se de 120 horas/aula. Após o curso, e ao retornar para Campina Grande, o Comandante do $2^{\circ}$ Batalhão de Polícia Militar (BPM) resolveu implementar algumas Bases de policiamento comunitário na cidade que se iniciou, segundo o citado Major, no bairro carente do Mutirão e depois no bairro do José Pinheiro, que era um local de alta incidência criminal. Em 2005, com a chegada de um novo Comandante, foram implementadas mais duas Bases. Por essa perspectiva, o projeto organizou-se de modo que foram estabelecidas a Base de Polícia Comunitária da Zona Oeste (bairro do Mutirão), Zona Leste (bairro do José Pinheiro), na Zona Norte e na Zona Sul da cidade.

No plano das dificuldades, destaca o Major Simão que

[...] obviamente a gente tem que dizer que não seguiu a teoria tendo em vista que nós tínhamos várias dificuldades. Primeiro porque era algo muito novo e também a necessidade do Comandante de fundar aquelas Bases e colocar o seu nome, vamos dizer assim, até porque não houve uma preparação pra aqueles policiais que iam trabalhar. Não houve uma capacitação adequada." (Informação verbal) ${ }^{6}$.

Inclusive o próprio Comandante do $2^{\circ} \mathrm{BPM}$ queria que a primeira Base Comunitária fundada tivesse um xadrez ${ }^{7}$, o que foi motivo de não-aceitação por parte do Major que acreditava que "[...] aqueles policiais que iam fazer essa relação com a comunidade local fizesse a prisão de alguém, apreendesse alguma pessoa, teria que encaminhar para Delegacia e não para a Base local. A Base local seria um local de discussão, de ampliar esse contato com a comunidade local." (Informação verbal) ${ }^{8}$. 
O trabalho inicial era sempre de sensibilização das comunidades. De início houve desconfiança por parte das comunidades e dos policiais, mas afirma o Major que com o tempo 0 projeto se consolidou e além da manutenção dos Conselhos Comunitários em cada um dos bairros, os quais exigiam justificativas dos policiais nas reuniões pela diminuição do policiamento nas devidas áreas, entre 2005 e 2006 cerca de 120 policiais participavam do projeto. Ainda assim, o Major entrevistado afirma que "[...] tinham alguns Comandantes que viam a experiência com bons olhos e que apoiavam, articulavam alguma coisa pra ajudar. Mas a grande maioria preferiu o modelo reativo que é o que aparece de forma midiática." (Informação verbal)9 .

Segundo o Major, o esfacelamento do projeto começou a acontecer em 2010, quando foi criado em Campina Grande o $10^{\circ} \mathrm{BPM}$, e as Bases Comunitárias foram divididas territorialmente quanto à esfera administrativa da Polícia Militar. Além disso, ocorreu um processo de descentralização, já que as Unidades Especializadas da Polícia Militar (Patrulhamento em motos - ROTAM -, Cavalaria, Força Tática, Policiamento de Choque) foram transferidas para as comunidades onde existiam as Bases Comunitárias como forma de manter e estreitar o relacionamento e, por fim, de acordo com as palavras do Major,

Com 0 início desse Governo ${ }^{10}$, nós podemos dizer que houve 0 que a gente denomina de uma descontinuidade daquilo que tinha iniciado, ou seja, a Agência de Governo preferiu denominar de outra forma e iniciar também, apesar da mesma perspectiva filosófica, mas que denominou com outro nome, e começou a surgir o que hoje tá se constituindo, são as Unidades de Polícia Solidária, que na verdade em Campina Grande a gente só veio a acontecer no ano de 2013. (Informação verbal) ${ }^{11}$.

Então, no que consiste o policiamento solidário?

As bases para a implantação do policiamento solidário em João Pessoa começaram no dia 20 de abril de 2011, com a inauguração da sede de Polícia Comunitária no bairro do Alto do Mateus. Ainda durante 0 ano de 2011 foram instaladas as Unidades de Polícia Solidária (UPS) nos bairros Mandacarú, Oitizeiro (Comunidade Bola na Rede) e São José.12 No dia 16 de setembro de 2012, o Jornal da Paraíba (SCARIONE, 2012) divulgava através da internet o suposto sucesso na implantação do policiamento comunitário em João Pessoa ao trazer como título da reportagem: "Polícia Solidária" ajuda a reduzir violência em JP. Ademais, destacava-se a informação de que "[...] estratégia de aproximação dos policiais com a população está ajudando a diminuir os índices de homicídio na capital." (SCARIONE, 2012). A reportagem enaltecia o fato de que as UPS trata-se de mais uma arma na redução do crime, além de proporcionar, segundo as palavras de um Tenente comandante de uma UPS, a satisfação dos moradores, já que são desenvolvidas ações de integração com a população através de palestras em escolas, creches, com líderes comunitários sobre assuntos voltados à violência doméstica, alcoolismo, doenças sexualmente transmissíveis. 
Tal reportagem foi divulgada dois meses depois do lançamento do Programa de policiamento solidário pelo Governo do Estado da Paraíba e pela Polícia Militar. Pouco mais de um ano após a implantação do projeto, por meio de notícia encontrada no site da Polícia Militar da Paraíba, no dia 15 de julho de 2013, veicula-se a comemoração desse primeiro ano do Programa de Polícia Solidária com a entrega de comendas às autoridades, inclusive ao governador do Estado da Paraíba. 0 que se destaca na notícia é que "O Polícia Solidária é mais uma ferramenta importante do Governo de promover a aproximação entre a polícia e a sociedade. É a oportunidade de mostrar ao cidadão qual o seu papel perante os órgãos de segurança pública." (SCARIONE, 2012). Desse modo, através do material divulgado pela imprensa, podemos sintetizar quais são os objetivos da criação da Polícia Solidária em João Pessoa, segundo o discurso oficial: reduzir o crime e garantir a aproximação entre polícia e sociedade.

\section{CONHECENDO O POSTO COMUNITÁRIO DO POLICIAMENTO SOLIDÁRIO}

Uma inscrição bíblica encontrada nas placas de inauguração dos postos de policiamento solidário em João Pessoa, e também destacada no muro da entrada da UPS de Mandacarú, serve-nos de referência para pensarmos esse projeto, ou seja, Bem aventurados os pacificadores, porque serão chamados filhos de Deus. Nesse caso, os pacificadores são os policiais militares, que devem estar engajados no processo de aproximação entre polícia e sociedade, demonstrando existir uma polícia mais democrática e cidadã. Nesse caminho, ter observado cotidianamente os postos de policiamento solidário revelou-me um projeto que se desenvolve numa rede de estratégias que visam à adaptação da atuação policial militar em bairros com características distintas, mas que independente das particularidades de cada posto, permitiu-me perceber o que pode ser comum a todos eles.

Em todos os postos observei que o serviço desempenhado pelos policiais militares se divide de duas formas: existem PMs que trabalham como permanentes, expressão nativa que caracteriza o policial que fica fixo no posto, atendendo à população local e, o outro modo diz respeito ao serviço reativo de rádio-patrulhamento, que funciona de acordo com o modelo antigo ou tradicional de polícia com acionamento da viatura via telefone mediante o 190 e despacho pela Central de Informações da Polícia Militar. Em nenhum dos postos existe policiamento a pé que siga as prescrições do que vem a ser o policiamento comunitário. Alguns deles também funcionam mediante o linha solidária, que diz respeito ao acionamento da viatura do bairro através de um telefone celular que os policiais utilizam na própria viatura, atendendo diretamente à população. 0 número encontra-se na viatura, mas esse serviço já não mais se encontra disponível em todas as UPS, assim como era quando se iniciou o projeto. 
Outra situação encontrada em todos os postos foi o fato de que a proposta inicial visava utilizar os policiais recém-formados no trabalho de policiamento solidário. Eles assim passavam por um curso de promotor de polícia comunitária por um período de uma semana antes de assumirem suas funções nos novos locais de trabalho. Segundo o quadro demonstrativo abaixo, a quantidade de policiais militares que fizeram o curso de Polícia Comunitária aumentou consideravelmente a partir do ano de 2011, data de criação das primeiras UPS.

Quadro 1 - PMs Capacitados em Polícia Comunitária na PMPB (1998-2013)

\begin{tabular}{|c|c|}
\hline Ano & Quantitativo \\
\hline 1998 & 49 \\
\hline 1999 & - \\
\hline 2000 & 01 \\
\hline 2001 & 36 \\
\hline 2002 & 42 \\
\hline 2003 & 15 \\
\hline 2004 & 42 \\
\hline 2005 & - \\
\hline 2006 & 08 \\
\hline 2008 & - \\
\hline 2009 & 70 \\
\hline 2010 & 179 \\
\hline 2011 & 173 \\
\hline 2012 & 360 \\
\hline 2013 & 679 \\
\hline Total & 652 \\
\hline
\end{tabular}

Fonte: Dados obtidos com Estado Maior Estratégico da Polícia Militar da Paraíba.

No entanto, durante as visitas, observei que existe um fluxo constante dos policiais que trabalham nas UPS. Muitos são ou já foram transferidos para outras Unidades. Misturam-se policiais que possuem o curso de policiamento comunitário com outros que não possuem, além de que o efetivo é formado por policiais com pouco tempo de serviço com outros que aguardam poucos meses para se reformarem, ou seja, no seio policial militar quer dizer: aposentarem-se. Alguns policiais que pertencem a outras Unidades de trabalho passam a tirar serviço ${ }^{13}$ nas UPS pela escala extra, que diz respeito a um policiamento remunerado que propicia ao policial militar trabalhar em suas horas de folga podendo escolher, até certo ponto, em qual local gostaria de desempenhar o seu serviço. Inclusive podendo deslocar-se para trabalhar em Batalhões ou Companhias de policiamento em outra cidade diferente de sua circunscrição. Tal fato enseja que, o policial que trabalha pelo extra, não fica necessariamente de forma fixa nas UPS. Um Tenente me relatou:

Às vezes um militar entra de férias aí encaixa outro que é de outro setor que não tem nada a ver com polícia comunitária, e quando esse militar volta de férias já não cabe ele aqui, já joga ele pra outro canto. Problema de tapar buraco na polícia militar. Aqui muitas vezes quando uma pessoa faz uma atitude negativa pra o Batalhão, ela é transferida pra aqui, pra base de Mandacarú, já vem aqui como se fosse um castigo. (Informação verbal) ${ }^{14}$. 
Como informa o entrevistado, alguns policiais são colocados para trabalhar nos postos como forma de castigo, ou seja, pelas palavras do mesmo Tenente da UPS de Mandacarú:

Se aquele militar cometeu uma atitude negativa pra o Batalhão e a Companhia entender que um trabalho ostensivo como é o trabalho aqui é negativo pra ele, ele não gosta, mandam ele pra aqui, como uma forma de punição. E aquele que gosta de trabalho ostensivo vai ser tirado daqui, botar numa custódia' ${ }^{15}$ ou na permanência”. (Informação verbal) ${ }^{16}$.

Um Cabo, que afirmou ter o curso de polícia comunitária, da UPS de Jaguaribe também me disse:

Nós sabemos que o serviço extra você tem o direito de escolher aonde você quer trabalhar pelo menos é o que diz o papel e quando a gente estava colocando, e lá na observação a gente colocava voluntário para tirar serviço na UPS de Jaguaribe, estava sendo remanejado para custódia, para guarda do presídio e eu me aborreci e deixei de colocar". (Informação verbal) $)^{17}$.

De todo modo, vejamos como podemos compreender melhor o funcionamento do projeto a partir do posto de polícia solidária do bairro de Mandacarú/Alto do Céu.

\subsection{A UPS de Mandacarú/Alto do Céu}

O posto de policiamento solidário do bairro de Mandacarú foi o segundo a ser inaugurado em João Pessoa, no dia 13 de outubro de 2011. Sua sede, apesar de estar situada em Mandacarú, também diz respeito à área do bairro vizinho conhecido por Alto do Céu. Em Mandacarú, o posto localiza-se no encontro entre as ruas José Alfredo de Ataíde e João de Brito Lima Moura, tendo à sua frente a rua João Fernando Vieira. Segundo dados do Instituto Brasileiro de Geografia e Estatística (IBGE, 2010), a população local no bairro de Mandacarú é de 12.593 habitantes e, o Alto do Céu possui uma população de 16.557 pessoas. No total, essa UPS está localizada numa área que serve ao todo 29.150 habitantes.

O posto funciona em um edifício composto de duas partes separadas. Em uma delas funciona a sede do Comando da UPS e, na outra, além de ser o ponto de funcionamento de atendimento ao público também existe um alojamento para os policiais com quarto, banheiro e cozinha. 0 policiamento no posto é realizado pela presença dos policiais permanentes, aqueles que ficam fixos no posto. Geralmente é uma dupla de policiais que trabalha como permanentes numa escala de 24 horas de serviço contínuo, com uma folga de três dias. O outro serviço dos policiais da UPS é aquele referente ao trabalho reativo, realizado pelos policiais nas viaturas. Existe também o policiamento efetuado em motos.

Segundo os dados coletados nas entrevistas, para que a UPS Mandacarú/Alto do Céu fosse inaugurada, foi preciso, cerca de dois meses antes da fundação, uma mega operação por parte 
AS ILUSÕES DO POLICIAMENTO COMUNITÁRIO: o caso da Paraíba

das forças policiais para a retomada do controle do bairro. Inclusive utilizaram um helicóptero da Polícia Militar de Pernambuco. Segundo as palavras de um Sargento:

Mandacarú estava sem controle. As áreas comerciais aqui no mínimo eram assaltadas duas
vezes ao dia, o mesmo estabelecimento. E no toque de recolher as ruas ao invés de serem
tomadas pela polícia estavam sendo tomadas pelos vândalos, pelos delinquentes. Foi um dia
de operação, agora foi uma operação que começou pela madrugada e se prolongou o dia
todo. (Informação verbal) ${ }^{18}$.

Após a suposta tomada do bairro, foi deslocado o primeiro efetivo para trabalhar na UPS. De acordo também com informações dos entrevistados, esse efetivo inicial (cerca de $70 \%$ dele) foi deslocado do Rancho do $1^{\circ}$ Batalhão de Polícia, ou seja, o local que funcionava como cozinha da Unidade Militar, que hoje se encontra desativado. Os policiais não possuíam o curso de polícia comunitária. Ainda mais que o prédio utilizado para a UPS tinha sido invadido por três famílias desabrigadas. Inicialmente os policiais montaram uma tenda no terreno e passaram a conviver com as famílias, de modo que depois foram conseguidas casas por parte do município para as famílias, fazendo com que a Polícia Militar assumisse o posto e o reformasse. No que concerne à atuação policial na área, os bairros de Mandacarú/Alto do Céu, de acordo com as estatísticas do Governo do Estado, são dois dos locais que apresentam os maiores índices de homicídio em João Pessoa. Como nos expõe um Capitão que trabalha na UPS:

Esta UPS cuida dos dois bairros: Mandacarú e Alto do Céu. E nós tivemos uma redução, em relação ao ano passado, até agora está em 33\% referente a 2013-2012. Então a nossa expectativa é que nós possamos cada vez mais baixar esses números. Tivemos, durante 0 ano de 2012, 27 homicídios em Mandacarú e estamos tentando bater esses números mês a mês. Apresentamos uma redução, agora no mês de setembro, em relação aos meses de 2012, uma redução de 33\%. A nossa perspectiva é que fechemos o ano de 2013 com pelo menos 20 homicídios. Aí nós estaríamos, pelo menos, batido a nossa meta. Se assim nós fecharmos com 20 homicídios, aí sim a gente vai reduzir em pelo menos $30 \%$ a relação anual do número de homicídios, que são os CVLI's. (Informação verbal) ${ }^{19}$.

Além da relação que existe entre a criminalidade e o número de homicídios, observamos uma lógica social presente no bairro, pautada pela falta de infraestrutura urbana, que se alia à presença do tráfico de drogas e do conflito entre facções rivais pelo controle dos pontos de venda de drogas. Segundo o relato dos policiais da UPS, os traficantes têm gerado o medo nas pessoas do bairro, o que causa o distanciamento entre policiais e moradores, pois,

Hoje já estamos visualizando pessoas que não quer que o policial passe e fale com ele [sic] fardado. A vagabundagem aqui está agindo da seguinte forma: se chegar fardado em qualquer residência, aquela pessoa que the recepcionou é tido como X-9. Então automaticamente ela vai ter duas opções: ou sair, abandonar a residência ou morrer. Se 0 vagabundo passar e ver uma das pessoas com telefone no ouvido já acha que tá ligando pra polícia. Antes procuravam, hoje é mais por telefone porque existe os olheiros aqui. (Informação verbal) ${ }^{20}$.

Um Tenente entrevistado relatou-me o seguinte fato (Figura 1):

Antigamente tinha o Seu Vavá ali na esquina que a gente ia tomava um café, tomava uma água, refrigerante, conversava e é um ponto estratégico. Outras pessoas vinham, 
conversavam com a gente, contavam histórias e alguns dias desses aí um criminoso aqui da área invadiu a barraca do Seu Vavá e disse que se visse a polícia lá mais uma vez ele ia matar Seu Vavá. A barraca existe há muito tempo e uma coisa que a polícia já fazia há muito tempo, hoje a gente não pode mais por causa desse tipo de atitude. (Informação verbal) ${ }^{21}$.

\section{Figura 1 - Uma rua inteira abandonada em Mandacarú por conta da violência}

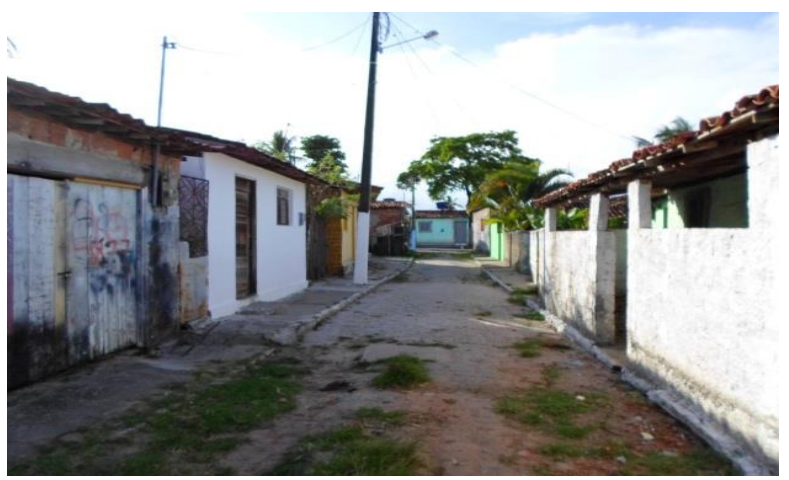

Fonte: Arquivos do autor (2013).

Segundo os policiais da UPS, a presença do tráfico tem distanciado os moradores da comunidade de procurar o posto para pedir auxílio e, cada vez mais, isso tem sido feito apenas mediante ligações telefônicas. A conjuntura do tráfico de drogas atuante na área da UPS tem se estabelecido por meio do conflito de duas facções rivais: a Okaida e os Estados Unidos. Durante as observações de campo, juntamente com as incursões policiais, pude perceber a deterioração dos locais onde essas supostas facções atuam, os quais são caracterizados pela pobreza e falta de saneamento básico (Figuras 2 e 3). Nesse sentido, a ausência de políticas estatais torna-se evidente como captado nas palavras de um Sargento entrevistado: "Se o Senhor chegar em uma dessas residências aqui, o cara tem que roubar, traficar pra sobreviver. Aqui nós já tivemos ocorrência de idosas com 85 anos sendo escravo do tráfico." (Informação verbal)22.

Figuras 2 e 3 - Inscrições com siglas que identificam as Facções que atuam nos bairros de Mandacarú/Alto do Céu: a Okaida (OKD) e Estados Unidos (EUA)

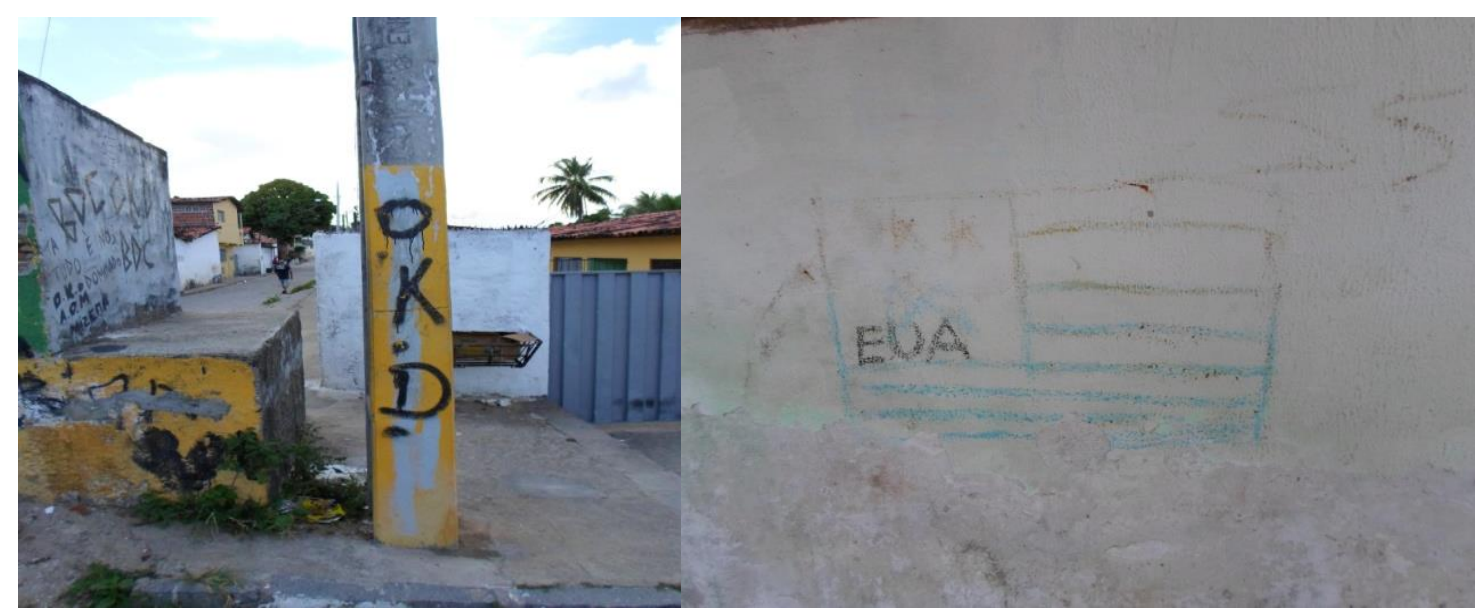

Fonte: Arquivos do autor (2013). 
Um Tenente da UPS também me esclareceu de quem se trata esses traficantes, pois, ao invés de chefes do tráfico, eles são utilizados pelos verdadeiros chefes que não se encontram no bairro (Figuras 4, 5, 6 e 7) e utilizam moradores locais para vender e distribuir a droga, de modo que

Exemplo é o Daniel, que é o chefe aqui do Beco de Zé Borges, se diz chefe, na verdade não é chefe de coisa nenhuma. É um cara que não tem onde cair morto. Em um local que tem um tráfico tão intenso como em Mandacarú um chefe do tráfico de droga não tem nem uma roupa pra usar direito. Há dez meses que eu tô aqui, há dez meses ele usa a mesma roupa, ou seja, não tem uma condição financeira pra um chefe do tráfico. (Informação verbal) ${ }^{23}$.

Figura 4, 5, 6 e 7 - Periferia do bairro de Mandacarú, locais onde, segundo os policiais militares da UPS, atuam os traficantes

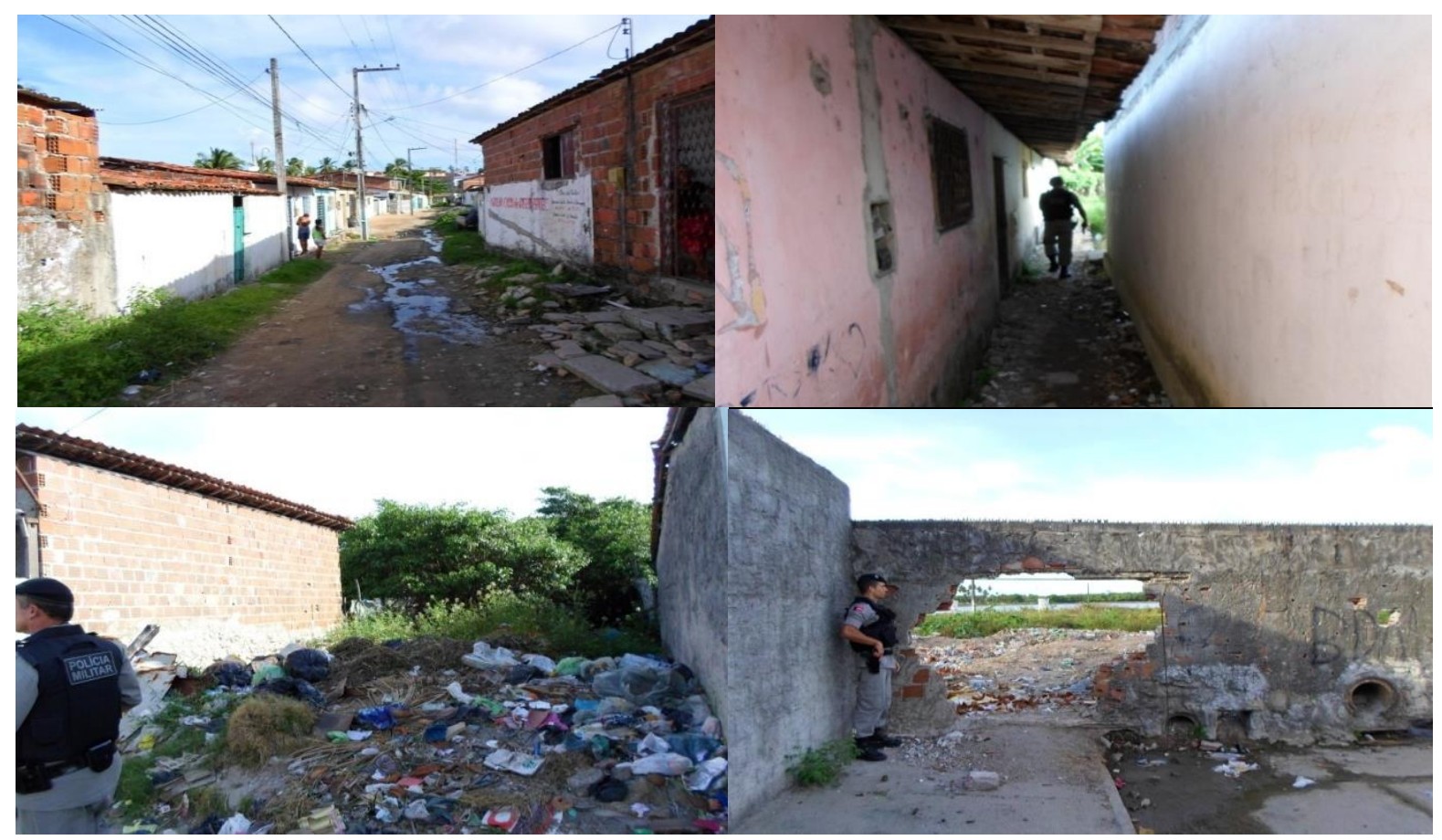

Fonte: Arquivos do autor (2013).

Assim, em meio ao que foi exposto sobre a realidade do projeto de policiamento solidário, destacamos o fato de que todo o discurso sobre um policiamento preventivo em torno do programa caminha paralelo com o paradoxal aumento do policiamento reativo e repressivo. (PASSOS, 2011). Antes da execução e efetuação do projeto, destacam-se estratégias que legitimam a presença cada vez maior dos policiais nos bairros assistidos pelo policiamento solidário. Aliás, a utilização do modelo tradicional de polícia faz parte do projeto, onde as viaturas policiais carregam o emblema Paraíba unida pela paz. Nesse caminho, a Paraíba tem feito parte de uma complexa dinâmica que envolve a violência e a criminalidade em nosso país, a qual nos cria a indagação de que, se as políticas de Segurança Pública visam à diminuição de crimes como os homicídios, como compreender a presença de políticas preventivas como o são as de policiamento comunitário? A resposta pode ser problematizada pelo fato de que se torna paradoxal o uso da prevenção diante do quadro de miséria social presente no bairro, 
fazendo com que se legitime o discurso da presença do Estado por meio da PM em sua atuação repressiva, mas discursivamente publicizada por uma atuação preventiva por meio do policiamento solidário.

\section{CONCLUSÃO}

Visamos demonstrar como se desenvolveu o policiamento comunitário no Estado da Paraíba enquanto política de Segurança Pública. Foi destacado que as tentativas para a implantação e manutenção do projeto de polícia comunitária vêm sendo realizadas desde o final da década de 90 do século passado, o que coincide com a busca, por parte da PM paraibana, de encontrar estratégias que a colocassem no caminho de encontro à democracia alcançada com o final do regime ditatorial e a promulgação da Constituição de 1988. Nosso trabalho baseou-se em dados obtidos em pesquisa anterior, mas que nos possibilitou compreender como o processo de implantação do policiamento comunitário, na Paraíba, como estratégia governamental-institucional, já dura cerca de vinte anos.

Após uma recapitulação histórica das primeiras tentativas e experiências, a ênfase maior recaiu sobre a descrição do atual modelo gestado e adotado pela PM na Paraíba: o policiamento solidário. $\mathrm{Na}$ análise de um dos postos pesquisados em momento anterior, como dito, onde o projeto atualmente se desenvolve (já que foi iniciado no ano de 2011), destacamos especialmente as dificuldades a partir das observações de campo e das falas dos policiais entrevistados, o que demonstrou que a presença da criminalidade e a falta de estrutura básica nos bairros fazem com que a presença da PM não seja a estratégia suficiente para falarmos de um sucesso do programa polícia solidária.

Acreditamos, por fim, que a partir de estratégias como a de polícia comunitária, devemos suscitar reflexões que coloquem em suspenso o que podemos considerar como sucesso alcançado, para não cairmos na ilusão de um Estado policial que se alimenta de ações democráticas que só impressionam o próprio público policial. Certamente, os desafios são imensos diante de tantos problemas encontrados na relação polícia e sociedade em nosso país. O que nos cabe, pelo menos, é problematizar o tema, o que, no nosso ponto de vista, já é um passo enriquecedor sob a perspectiva da crença policial militar.

\section{REFERÊNCIAS}

ALBERNAZ, E. R. et. al. Tensões e desafios de um policiamento comunitário em favelas do Rio de Janeiro: o caso do grupo de policiamento em áreas especiais. São Paulo em perspectiva, São Paulo, v. 21, n. 2, p. 39-52, 2007. Disponível em: http://www.seade.gov.br. Acesso em: 28 dez. 2018. 
BEATO, C. Reinventando a polícia: a implementação de um programa de policiamento comunitário. In: BEATO, C. Policiamento comunitário: experiências no Brasil 2000-2002. São Paulo: Página Viva, 2002. p. 113-165.

BRASIL. Ministério da Justiça e Segurança Pública. Secretaria Nacional de Segurança Pública. Matriz curricular nacional para ações formativas dos profissionais da área de segurança pública. Brasília, DF, 2009. Disponível em: http://ensino.senasp@mj.gov.br. Acesso em: 15 dez 2018.

BRASIL. Ministério da Justiça. Plano Nacional de Segurança Pública. Brasília, DF, 2000.

BRASIL. Presidência da República. Casa Civil. Subchefia para assuntos jurídicos. Lei no 10.201, de 14 de fevereiro de 2001. Institui o Fundo Nacional de Segurança Pública - FNSP, e dá outras providências. Diário Oficial da União, Brasília, DF, 2001.

CERQUEIRA, C. M. N. Do patrulhamento ao policiamento comunitário. Rio de Janeiro: Freitas Bastos, 1999.

GOTTARDO, L. P. de S.; SILVA, P. J. S. da. Proposta de metodologia de implementação da filosofia de polícia comunitária no Estado de Rondônia. In: SCHNEIDER, R. H. (org.) Abordagens atuais em segurança pública. Porto Alegre: EDIPUCRS, 2011. p. 275-285.

GREENE, J. R. Avaliando as estratégias planejadas de mudança no policiamento moderno: implementando o policiamento comunitário. In: BRODEUR, J.-P. Como reconhecer um bom policiamento: problemas e temas. São Paulo: editora da Universidade de São Paulo, 2002. p. 175196.

INSTITUTO BRASILEIRO DE GEOGRAFIA E ESTATÍSTICA. Censo Demográfico. Rio de Janeiro, 2010.

KAHN, T. Velha e nova polícia: polícia e políticas de segurança pública no Brasil atual. São Paulo: Sicurezza, 2002.

LEEDS, E. Agentes de mudança em instituições resistentes: Nazareth Cerqueira e o desafio da reforma da segurança Pública no Brasil. In: LIMA, R. S. de; BUENO, S. (orgs.). Polícia e democracia: 30 anos de estranhamento e esperanças. São Paulo: alameda, 2015. p. 17-38.

LIMA, E. B. de; MATIAS DA SILVA, J. A experiência de policiamento comunitário nos bairros de Paratibe e Muçumago em João Pessoa-PB. In: LIMA, E. B. de Polícia e sociedade: práticas e saberes no campo da integração da segurança pública. Rio de Janeiro: Viva Rio e Konrad Adenauer, 2010. p. 58-70.

MELO, T. de S. Policiamento comunitário no Rio de Janeiro: uma estratégia de ampliação do controle social no contexto do neoliberalismo. 2009. Dissertação (Mestrado em Sociologia e Direito) Universidade Federal Fluminense, Niteroi, RJ, 2009.

MESQUITA NETO, P. de. Ensaios sobre segurança cidadã. São Paulo: QuartierLatin; Fapesp, 2011.

MOORE M. H. Policiamento comunitário e policiamento para a solução de problemas. In: TONRY, M.; MORRIS, N. (Orgs.). Policiamento moderno. São Paulo: Editora da Universidade de São Paulo, 2003. p. $115-175$. 
MUNIZ, J. de $O$ et al. Resistências e dificuldades de um programa de policiamento comunitário. Tempo Social: revista de Sociologia da USP, São Paulo, v. 9, n. 1, p. 197-213, 1997.

PARAÍBA (Estado). Plano Estadual de Segurança Pública. João Pessoa, 2003-2006.

PASSOS, G. da R. "Segurança pública não é só polícia!": segurança e participação social em relação ao policiamento comunitário na cidade de Aracajú. 2011. Tese (Doutorado em Sociologia) Universidade Federal da Bahia, Salvador, BA, 2011.

ROSENBAUM, D. P. A mudança no papel da polícia: avaliando a transição para policiamento comunitário. In: BRODEUR, J.-P. Como reconhecer um bom policiamento: problemas e temas. São Paulo: Editora da Universidade de São Paulo, 2002. p. 27-55.

SÁ, L. D. de. Os filhos do Estado: Auto-imagem e disciplina na formação dos oficiais da polícia militar do Ceará. Rio de Janeiro: Relume Dumará, 2002.

SCARIONE, M. "Polícia solidária" ajuda a reduzir violência em JP. Jornal da Paraíba, João Pessoa, 2012. Disponível em: http://www.jornaldaparaiba.com.br/noticia/91914_policia-solidaria-ajuda-a-reduzirviolencia-em-jp. Acesso em: 16 dez 2018.

SILVA, J. M. da. Polícia comunitária e democracia - um novo modo de se fazer segurança pública na Paraíba. In RATTON, J. L.; BARROS, M. (coord.). Polícia, democracia e sociedade. Rio de Janeiro: Editora Lumen Juris, 2007. p. 265-279.

SKOGAN, W G. Participação da comunidade e policiamento comunitário. In: BRODEUR, J.-P. Como reconhecer um bom policiamento: problemas e temas. São Paulo: editora da Universidade de São Paulo, 2002. p. 119-138.

SKOLNICK, J. H.; BAYLEY, D. H. Policiamento comunitário: questões e práticas através do mundo. São Paulo: Editora da Universidade de São Paulo, 2002.

TROJANOWICZ, R.; BUCQUEROUX, B. Policiamento comunitário: como começar. Rio de Janeiro: Polícia Militar do Estado do Rio de Janeiro, 1994.

\section{Notas}

${ }^{1}$ As PMs, por terem herdado as formas de organização do Exército brasileiro, dividem seu sistema hierárquico em dois quadros distintos: o das Praças (Soldado, Cabo, Terceiro-Sargento, Segundo-Sargento, Primeiro-Sargento e Subtenente) e dos Oficiais (Segundo-Tenente, Primeiro-Tenente, Capitão, Major, Tenente-Coronel e Coronel). Segundo Sá (2002, p. 30, grifo do autor), "Oficiais e Praças são princípios de divisão que produzem visões específicas no interior da organização: de um lado, estão os comandantes e, de outro, os subordinados respectivamente, as 'cabeças pensantes' da corporação e a tropa".

2 Existem mais de cinco postos de polícia solidária na cidade de João Pessoa e em cidades da região metropolitana.

3 Ver em Policiamento comunitário: experiências no Brasil 2000 - 2002. São Paulo: Página Viva, 2002.

${ }^{4}$ Referimo-nos aqui especificamente às Polícias Militares.

${ }^{5}$ Depoimento retirado da entrevista realizada em 17/10/2013.

${ }^{6}$ Depoimento retirado da entrevista realizada em 17/10/2013 


\section{AS ILUSÕES DO POLICIAMENTO COMUNITÁRIO: o caso da Paraíba}

${ }^{7}$ Nome popular no seio policial para denominar as celas onde são colocadas as pessoas que são presas pela Polícia Militar e entregues à Polícia Civil nas Delegacias.

8 Depoimento retirado da entrevista em 17/10/2013

9 Depoimento retirado da entrevista realizada em 17/10/2013

10 O entrevistado se refere ao Governo da Paraíba sob a direção do Governador Ricardo Coutinho, que governou entre os anos de 2011 e 2018.

11 Depoimento retirado da entrevista realizada em 17/10/2013.

12 Unidades de polícia solidária (UPS - s. d.).

${ }^{13} \mathrm{Na}$ linguagem policial militar é o mesmo que trabalhar. Como quando se indaga Você vai tirar serviço onde?, ou seja, qual será seu local de trabalho.

14 Depoimento retirado da entrevista realizada em 15/10/2014.

15 Tipo de policiamento no qual os policiais ficam no acompanhamento de presos que se encontram internos em hospitais.

16 Depoimento retirado da entrevista em 15/10/2014.

17 Depoimento retirado da entrevista em 15/10/2014.

18 Depoimento retirado da entrevista realizada em 30/10/2014.

19 Depoimento retirado da entrevista realizada em 17/09/2013.

20 Depoimento retirado da entrevista realizada em: 30/10/2014.

21 Depoimento retirado da entrevista realizada em 15/10/2014.

22 Depoimento retirado da entrevista realizada em 30/10/2014.

23 Depoimento retirado da entrevista realizada em 15/10/2014. 